\title{
Variations in prevalence and conduct of school food gardens in tropical and subtropical regions of north-eastern Australia
}

\author{
Shawn Somerset* and Antoine Bossard \\ School of Public Health and Heart Foundation Research Centre, Griffith University, University Drive, \\ Meadowbrook, Queensland 4131, Australia
}

Submitted 31 August 2007: Accepted 18 November 2008: First published online 15 January 2009

\begin{abstract}
Objectives: To determine the prevalence and usage of food gardens in primary schools in three distinct climatic regions of north-eastern Australia.

Design: Cross-sectional surveys combining quantitative and qualitative data collection. Two separate telephone questionnaires were developed and implemented, according to the presence or absence of a food garden within the school. Main outcome measures were answers to scaled response and open-ended questions related to factors supporting and inhibiting the establishment and sustainability of school food gardens.

Setting: All state primary schools in three disparate regions of the north-eastern Australian state of Queensland were asked to participate in the study.

Results: A total of $71 \%$ ( $n$ 128) of schools agreed to participate. Of these, thirtyseven primary schools had functioning food gardens. The variations in prevalence between regions combined with respondent views indicated climate as a major factor affecting the success of food gardens. Gardens were often used as a tool by schools to teach science, environment or social skills. Gardening activities were generally linked to curriculum studies on plants, fruit and vegetable intake, and healthy eating. The main issues for schools and teachers in establishing food gardens were the time required and the lack of personnel to coordinate garden activities. Of the schools with food gardens, $92 \%$ believed their garden had been a success. Conclusions: The study revealed strong grass-roots support for school-based food gardens. Although climate and location were important factors associated with the presence of a functioning food garden, respondents nominated teacher involvement and sustained motivation as essential factors for successful school food gardens.
\end{abstract}

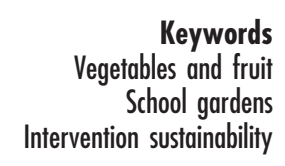

The rising prevalence of overweight and obesity in all age groups continues to be an international public health priority. Of particular concern is the increased risk of metabolic syndrome (complications involving dyslipidaemia, hypertension and diabetes) associated with higher $\mathrm{BMI}^{(1)}$. Excessive body weight has also been associated with increased risk of some forms of cancer ${ }^{(2)}$.

It is well established that early intervention is an integral step in the prevention of such diseases ${ }^{(3)}$, with major international initiatives focusing on enhancing diet, especially vegetable and fruit intake, in children ${ }^{(4)}$. There is compelling evidence that vegetable and fruit consumption is driven by knowledge of and attitudes towards such foods, and that instituting changes to these factors in children can influence consumption during subsequent life-cycle stages ${ }^{(5)}$. This relationship is also implied in many school-based interventions aiming to influence awareness by increased availability of and exposure to a wider range of vegetables and fruits, and improve self-efficacy to enhance vegetable and fruit consumption ${ }^{(6,7)}$.
The potential for community gardening to enhance the health of participants and their communities is well established. Benefits extend from enhancement of dietary intake and physical activity, through to a range of psychosocial and economic factors underpinning individual and community health ${ }^{(8,9)}$. The ability of community gardening to impact on multiple determinants of health represents a further advantage, since recent evidence suggests that effective reduction of overweight and obesity prevalence is linked to interventions which combine physical activity and dietary behaviour change ${ }^{(10)}$, rather than treating these important determinants as mutually exclusive.

Schools are one environment within which community gardens have flourished. School food gardens offer a setting where multiple health determinants (diet, physical activity, social connection) are integrated into a single activity $^{(9,11-14)}$. Growing evidence supports the potential of school-based food gardens as a useful nutrition education tool, and there is general agreement that gardens can be a useful addition to school resources ${ }^{(8)}$. 
An expanding empirical literature is available on the potential for gardening to affect dietary behaviour change in school-aged children ${ }^{(9)}$. Lautenschlager and Smith ${ }^{(13)}$ reported recently that a 10 -week garden-based food education programme had positive effects on the planned behaviour of a group of youths aged 8 to 15 years, in terms of a desire to learn more about gardening, nutrition, cooking and food choice. In a study which involved the establishment of a school garden on-site, McAleese and Rankin $^{(15)}$ observed increases in self-reported vegetable and fruit intake in a group of youths aged 10 to 13 years, in response to a formal 12-week garden-based nutrition education programme.

Health is often not the primary motivation for establishment of gardens in schools, but more a collateral effect. More pressing issues such as fund raising and behaviour management are often cited as the primary reasons for establishing gardens in schools ${ }^{(9)}$. Notwithstanding the initial motivations for installation of gardens in schools, a key sustainability issue for such gardens is successful integration as a teaching resource in a broad spectrum of the curriculum.

A previous pilot study in a smaller area of the northeastern state of Australia revealed that approximately one-quarter of primary schools in a defined geographical area had a functioning school food garden ${ }^{(9)}$. This prevalence was in the absence of any centralized initiative by the local state education authority to promote or coordinate such activity. The present study sought to determine the prevalence of school food gardens in a broader range of geographical (and climatic) education regions and identify factors integral to the establishment and sustainability of such gardens.

\section{Methods}

\section{Study population}

All state primary schools in three defined state government education regions in Queensland were contacted by telephone and asked to participate. Characteristics of the three regions were: (i) tropical continental/monsoonal (Mount Isa region, $n$ 17); (ii) tropical humid (Cairns and Cape York districts); and (iii) subtropical metropolitan (north Brisbane region comprising four inner metropolitan districts, Geebung, Corinda, Stafford and Murrumba, $n$ 117). These regions are shown in the context of Queensland and Australia in Fig. 1.

\section{Climate of survey regions}

\section{Tropical continental/monsoonal region}

The climate of this region (Mount Isa to the Gulf of Carpentaria; approximately $310000 \mathrm{~km}^{2}$ ) is governed by its tropical location (latitude), elevation and distance from the coast. The climate is described as 'tropical continental' with three main seasons: (i) mild temperatures with low humidity (May to August); (ii) hot temperatures with low humidity (September to December); and (iii) hot temperatures with high humidity (January to April). The annual rainfall inland can vary from 250 to $>500 \mathrm{~mm}$. The wet season usually occurs from December to March, with $>75 \%$ of the annual rainfall. During the hot season,

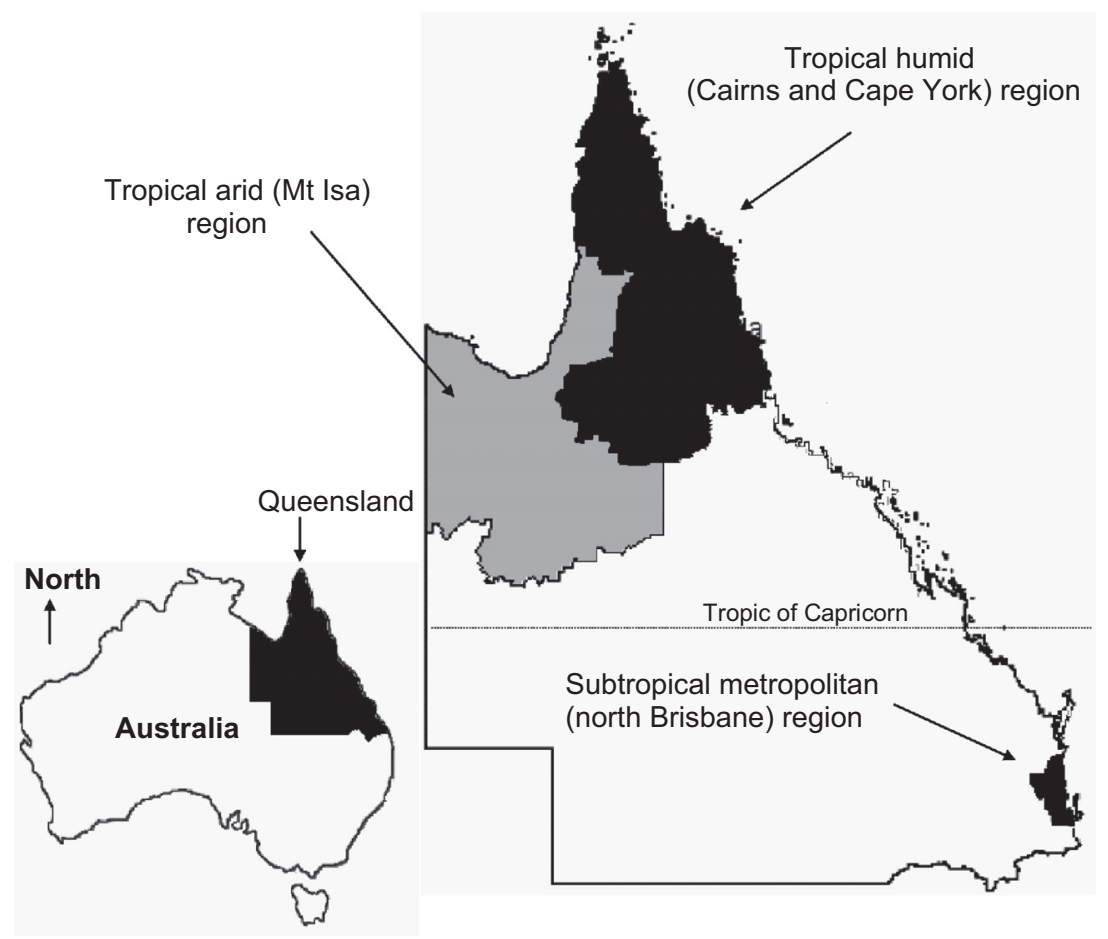

Fig. 1 Location of the study regions 
temperatures are often $>40^{\circ} \mathrm{C}$ with about $230 \mathrm{~d}$ with temperatures above $35^{\circ} \mathrm{C}$. Along the coastal areas, temperatures are cooler with a higher annual rainfall. Temperatures are often between 30 and $40^{\circ} \mathrm{C}$ and the annual rainfall is $>1200 \mathrm{~mm}$, with $>75 \%$ occurring during January, February and $\operatorname{March}^{(16)}$

\section{Tropical bumid region}

In this region (Cairns and Cape York; approximately $270000 \mathrm{~km}^{2}$ ), the east coast has a tropical climate, with generally hot, humid summers and mild, drier winters. The average annual rainfall is $1992 \mathrm{~mm}$, with the majority occurring during summer between January and March. Temperatures usually range from 23 to $31^{\circ} \mathrm{C}$ in summer and from 18 to $26^{\circ} \mathrm{C}$ in winter. The west coast has a tropical monsoonal climate with a distinct wet and dry season. The average annual rainfall is $>2000 \mathrm{~mm}$, mostly occurring from December to March. Very little rainfall is reported from May to September. Cyclones regularly affect both coasts ${ }^{(16)}$.

\section{Subtropical metropolitan region}

Brisbane is a large metropolis (population approximately 1.8 million) located $768 \mathrm{~km}$ south of the Tropic of Capricorn. The region (northern Brisbane) has a subtropical climate with hot, humid summers and clear, mild winters. Temperatures in summer are usually between 20 and $30^{\circ} \mathrm{C}$, whereas in winter, the dry season, temperatures range between 10 and $20^{\circ} \mathrm{C}$. Annual rainfall is about $1000 \mathrm{~mm}$ and mostly during summer ${ }^{(16)}$.

\section{Description of the questionnaires}

Two separate telephone surveys were used in the present study: one for schools that currently had a food garden or had one in the recent past (Garden+) and a second (shorter) survey for schools that currently did not have a food garden and did not have one in the recent past (Garden-). Both surveys were based largely on questions from a questionnaire used previously for face-to-face interviews in a pilot study to understand the nature of food gardens in primary schools within another geographical region in north-eastern Australia ${ }^{(9)}$. The surveys were expanded from that used previously by incorporating issues identified in that pilot study.

The Garden+ survey incorporated both scaled response and open-ended questions covering four themes: (i) characteristics of the school food garden and its establishment (five open-ended questions, three scaled response questions); (ii) the use of the garden by both students and teachers (six open-ended questions, eighteen scaled response questions); (iii) school activities related to the garden (nine scaled response questions); and (iv) respondent attitudes towards their garden (five open-ended questions, five scaled response questions). The first part of the Garden+ survey focused on details about the school food garden such as budget, size, people responsible for the care of the garden, whether or not the garden was used for school activities during class time, and the extent of parental involvement in the garden. The second and largest part of the questionnaire focused on how students and teachers used the garden. Questions were asked relating to issues such as which foods were the easiest to grow, which students preferred, which were the most useful from an education perspective, estimates of time children spent in the garden, people most involved in the conduct of garden activities, approximate percentage of students taking part in garden activities, identification of curriculum areas relevant to garden activities, and student enjoyment and enthusiasm for working in the garden. The third part of the questionnaire involved scaled response questions to ascertain the most prevalent class activities associated with the garden. The final part comprised a series of open-ended questions covering future intentions related to the garden and a general impression of the effect of the garden on students. Each interview using the Garden + survey took between 30 and $60 \mathrm{~min}$ to complete.

The shorter Garden - survey was established to identify needs for and potential barriers to the establishment of gardens in such schools. The Garden- survey comprised a series of eight closed and seven open-ended questions on perceived usefulness of, interest in and barriers to establishing a garden within the school. Telephone interviews using the Garden - survey took approximately $5 \mathrm{~min}$ to complete.

Drafts of both surveys were tested for comprehension and relevance in two schools outside the sample (one with and one without a food garden), and a small number of minor modifications were made on the basis of comments by interviewees to enhance the conduct of telephone interviews. Schools were first contacted by telephone to determine if the school had a history of gardening and to determine which of the two surveys to implement. An appointment for a telephone interview was then arranged with the teacher responsible for the garden or, in the case of no garden, the principal of the school.

\section{Data analysis}

Quantitative data were entered into the SPSS statistical software package version $13 \cdot 0$ (SPSS Inc., Chicago, IL, USA), which was used to calculate descriptive statistics and for comparison of means ( $\chi^{2}$ analysis for scaled response questions and Student's $t$ test for demographic data). Responses to open-ended questions were transcribed verbatim and common themes identified. Responses to scaled response questions were treated as ordinal data for the purposes of $\chi^{2}$ analysis.

\section{Results}

A total of $71 \%$ of the schools contacted agreed to participate in the study, comprising 66\%, 79\% and $82 \%$ of 
Table 1 Prevalence of school gardens according to geographical region, north-eastern Australia

\begin{tabular}{|c|c|c|c|c|c|c|c|c|c|}
\hline \multirow[b]{2}{*}{ Region } & \multirow[b]{2}{*}{ Total no. of schools } & \multicolumn{2}{|c|}{ Have a food garden* } & \multicolumn{2}{|c|}{ Establishing onet } & \multicolumn{2}{|c|}{ Garden previously } & \multicolumn{2}{|c|}{ No garden§ } \\
\hline & & $n$ & $\%$ & $n$ & $\%$ & $n$ & $\%$ & $n$ & $\%$ \\
\hline Subtropical metropolitan & 117 & 24 & $20 \cdot 5$ & 3 & $2 \cdot 6$ & 3 & $2 \cdot 6$ & 87 & $74 \cdot 4$ \\
\hline Tropical humid & 47 & 12 & $25 \cdot 5$ & 2 & $4 \cdot 3$ & 4 & $8 \cdot 5$ & 29 & $61 \cdot 7$ \\
\hline Tropical continental/monsoonal & 17 & 1 & $5 \cdot 9$ & 0 & - & 4 & $23 \cdot 5$ & 12 & $70 \cdot 6$ \\
\hline Total & 181 & 37 & $20 \cdot 4$ & 5 & $2 \cdot 8$ & 11 & $6 \cdot 1$ & 128 & $70 \cdot 7$ \\
\hline
\end{tabular}

${ }^{*}$ A functioning garden was at the school at the time of interview.

†The school was in the process of establishing the garden, but it was not yet functional.

$\ddagger$ There had been a garden at the school, but not within the past two years.

$\S$ No record of a garden ever having been established at the school.

schools approached from the subtropical metropolitan, tropical humid and tropical continental regions, respectively. The prevalence of school food gardens according to these regions is outlined in Table 1 . The mean size of schools was significantly different between the tropical continental and subtropical metropolitan regions $(P<$ $0 \cdot 05)$. However, no difference in the mean size of schools with and without gardens was detected.

\section{Schools with a food garden}

Most gardens had been established recently (75\% were less than 3 years old) although several school food gardens were more than 10 years old. Gardens usually occupied between 10 and $50 \mathrm{~m}^{2}$ of space. Just over half (55\%) the schools reported the budget for establishing these gardens as being less than AUD\$50. There was a general tendency (non-significant) for gardens in the tropical regions to be larger that those reported in the subtropical metropolitan region.

The initial aims for establishing vegetable gardens varied across a range of issues (see Table 2). Most schools used the garden for class activities and teachers were the most prominent individuals involved in the regular care of the garden (they usually were in charge of the garden but sometimes with the assistance of others such as employed groundspeople or parents). Students were also prominent in the care of the garden. In both subtropical metropolitan and tropical humid areas, more than $30 \%$ of schools reported significant parental involvement in garden activities, in contrast to the tropical continental region where it was very low.

Almost all schools grew the same vegetables, principally tomatoes ( $82 \%$ ), lettuce ( $71 \%$ ) and herbs (58\%), since these were reported to be the easiest to grow. Fruits were less frequent in gardens, although some schools (32\%) in the subtropical metropolitan region grew strawberries. Other vegetables such as corn, carrots and beans were also grown in some gardens. The most common fruits grown in the tropical regions were watermelon and papaya. In the tropical humid region, $62 \%$ of gardens grew corn. In schools across all regions, lettuce was nominated as the easiest vegetable to grow (29\%), followed by herbs and tomatoes. In the tropical humid region, some schools reported
Table 2 Frequency of responses for schools with gardens ( $n 37)$ to the open-ended question 'What were the initial aims for establishing the garden?'

\begin{tabular}{lll}
\hline Initial aim & $n$ & $\%$ \\
\hline Learn about vegetables and fruit & 8 & 22 \\
Learn about gardening & 8 & 22 \\
Study with the garden & 7 & 19 \\
Real life example & 6 & 16 \\
Produce food & 5 & 14 \\
Study growing life & 4 & 11 \\
Project for school & 4 & 11 \\
Learn responsibility & 3 & 8 \\
Supply school canteen & 3 & 8 \\
Learn healthy eating & 3 & 8 \\
Associate with lunch clubs & 3 & 8 \\
Learn social skills & 2 & 5 \\
Enhance community & 2 & 5 \\
Learn cooking & 1 & 3 \\
\hline
\end{tabular}

having a pumpkin competition, where they tried to grow the largest pumpkin. They also referred to a competition between several schools in the region concerning growing vegetables. No specific plants were nominated as being particularly useful for education purposes, or preferred by the children.

Climate appeared to have a major influence on the sustainability of school gardens, with many gardens having failed in the tropical continental region (see Table 1). Schools without gardens also noted climate as a major barrier, with the weather being usually too hot to grow plants during summer months, particularly inland in the tropical continental region. A straightforward solution put forward by some schools from the tropical humid region was a move towards growing tropical plants such as corn, peanut or bok-choi. Some respondents noted that this also presented opportunities for expansion of understanding food cultures from non-European origins.

A large proportion (61\%) of schools in the present study used the garden on average for 2 to $4 \mathrm{~h} /$ week and sometimes more ( $21 \%$ used it for 4 to $6 \mathrm{~h} /$ week). A total of $42 \%$ of schools noted students usually spending about 30 to $60 \mathrm{~min}$ in the garden per week. Students took part in garden activities often during school time (61\%) but some did the garden specifically as a lunchtime activity. Most schools (69\%) coordinated students to work in the 
garden in small groups, to learn teamwork and social skills. Students were generally reported as being enthusiastic about garden-related activities (more than 50\% of schools reported their students being very keen on working in the garden). There was no clear difference reported between boys' and girls' attitudes to work in the garden.

About one-third of all schools reported using their garden extensively as a teaching tool (involved in most curriculum areas). This was particularly the case for smaller schools, since there was a tendency for large schools to use their gardens in a more limited fashion. Indeed, for larger schools, the use of the garden was often restricted to only one or a few classes or for a special unit (for $59 \%$ of the schools, less than $25 \%$ of the students took part in the garden activities). In the tropical humid region for instance, the average percentage of participation in garden activities was 55\% (in a third of the schools, all students took part in garden activities; $75 \%$ of these schools had less than thirty students).

Most schools used their garden during formal study periods (see Table 3). In relation to class-based activities, most teachers reported using the garden for topics such as nutrition, plant growth and healthy eating (see Table 4). Although trends in differences between regions are apparent in Tables 3 and 4, these differences did not achieve statistical significance ( $\chi^{2}$ analysis). More than $60 \%$ thought that the garden had an influence on students' eating habits at home and at school through effects such as bringing healthy lunches, trying new vegetables, taking vegetables home and cooking them with their families, or even starting a vegetable garden at home.

Some schools used the garden as a lunch club where each student interested in gardening could participate, so that only interested and involved students took part in gardening activities. Most of these reported wanting to extend the use and size of the garden, but issues such as the time required to expand and tend a larger garden and competition with other initiatives within the school were identified as barriers.

A large majority of schools (92\%) indicated their garden as a 'real success' and $91 \%$ indicated they intended to continue it for next year. A large proportion (74\%) wanted to expand their garden, introduce more students

Table 3 Frequency of responses for schools ( $n$ 48) with gardens (past or present) to the question 'How do/did teachers used the garden?' according to geographical region

\begin{tabular}{|c|c|c|c|c|c|c|c|c|c|c|c|c|c|c|c|c|}
\hline \multirow[b]{2}{*}{ Response } & \multicolumn{4}{|c|}{$\begin{array}{c}\text { Subtropical } \\
\text { metropolitan ( } n \text { 27) }\end{array}$} & \multicolumn{4}{|c|}{$\begin{array}{c}\text { Tropical } \\
\text { humid }(n 16)\end{array}$} & \multicolumn{4}{|c|}{$\begin{array}{c}\text { Tropical } \\
\text { continental/monsoonal }(n 4)\end{array}$} & \multicolumn{4}{|c|}{$\begin{array}{l}\text { Total } \\
(n 48)\end{array}$} \\
\hline & $U$ & $\mathrm{O}$ & $S$ & $\mathrm{~N}$ & U & $\mathrm{O}$ & $S$ & $\mathrm{~N}$ & U & $\mathrm{O}$ & $S$ & $\mathrm{~N}$ & U & O & $S$ & $\mathrm{~N}$ \\
\hline Maths & 2 & 8 & $9^{*}$ & 3 & 3 & $4^{*}$ & 3 & 1 & $3^{*}$ & 0 & 0 & 0 & 8 & $12^{*}$ & $12^{*}$ & 4 \\
\hline Science & 4 & $12^{*}$ & 6 & 0 & 1 & $8^{*}$ & 1 & 1 & 1 & 2 & 0 & 0 & 6 & $22^{*}$ & 7 & 1 \\
\hline Literacy & 4 & 8 & $9^{*}$ & 1 & 3 & $4^{*}$ & 2 & 2 & $3^{*}$ & 0 & 0 & 0 & 10 & $12^{*}$ & 11 & 3 \\
\hline Health/nutrition & 4 & $13^{*}$ & 4 & 1 & 2 & 3 & $5^{\star}$ & 1 & $3^{*}$ & 0 & 0 & 0 & 9 & $16^{*}$ & 9 & 2 \\
\hline Environment & 5 & $12^{*}$ & 5 & 0 & 2 & $5^{*}$ & 3 & 1 & $3^{*}$ & 0 & 0 & 0 & 10 & $17^{*}$ & 8 & 1 \\
\hline Drawing/art & 2 & 3 & $10^{*}$ & 5 & 1 & 2 & $4^{*}$ & 3 & $3^{*}$ & 0 & 0 & 0 & 6 & 5 & $14^{*}$ & 8 \\
\hline Physical activity & 3 & 6 & $9^{*}$ & 3 & 2 & 3 & $4^{*}$ & 1 & $3^{*}$ & 0 & 0 & 0 & 8 & 9 & $13^{*}$ & 4 \\
\hline Music & 0 & 0 & 5 & $15^{*}$ & 1 & 0 & 3 & 6 & 0 & 0 & 1 & $2^{*}$ & 1 & 0 & 9 & $23^{*}$ \\
\hline Social skills & 8 & $10^{*}$ & 2 & 1 & 3 & $5^{*}$ & 2 & 1 & $3^{*}$ & 0 & 0 & 0 & 14 & $15^{*}$ & 4 & 2 \\
\hline Behaviour management & 2 & $13^{*}$ & 2 & 4 & 0 & $5^{*}$ & 2 & 3 & $1^{*}$ & $1^{*}$ & $1^{*}$ & 0 & 3 & $19^{*}$ & 5 & 7 \\
\hline Fund raising & 1 & 7 & 3 & $9^{*}$ & $3^{*}$ & $3^{*}$ & $3^{*}$ & 1 & 0 & 0 & 1 & $2^{*}$ & 4 & $10^{*}$ & 7 & $12^{*}$ \\
\hline Tuck shop & 0 & 2 & 4 & $13^{*}$ & 0 & 2 & 3 & 6 & 0 & 0 & 0 & $3^{*}$ & 0 & 4 & 7 & $22^{*}$ \\
\hline
\end{tabular}

$\mathrm{U}=$ usually; $\mathrm{O}=$ often; $\mathrm{S}=$ sometimes; $\mathrm{N}=$ never.

*Mode response.

Table 4 Frequency of responses for schools ( $n 48)$ with gardens (past or present) to statements related to the use of school gardens in the classroom

\begin{tabular}{|c|c|c|c|c|c|c|c|c|c|c|c|c|}
\hline \multirow[b]{2}{*}{ Statement } & \multicolumn{3}{|c|}{$\begin{array}{c}\text { Subtropical } \\
\text { metropolitan ( } n \text { 27) }\end{array}$} & \multicolumn{3}{|c|}{$\begin{array}{c}\text { Tropical } \\
\text { humid }(n \text { 16) }\end{array}$} & \multicolumn{3}{|c|}{$\begin{array}{c}\text { Tropical } \\
\text { continental/monsoonal }(n 4)\end{array}$} & \multicolumn{3}{|c|}{$\begin{array}{l}\text { Total } \\
(n \text { 48) }\end{array}$} \\
\hline & A & SA & $\mathrm{D}$ & A & SA & $\mathrm{D}$ & A & SA & $\mathrm{D}$ & $A$ & SA & $\mathrm{D}$ \\
\hline Students like vegetable activities & 8 & $10^{*}$ & 0 & $7^{*}$ & 2 & 0 & 1 & $2^{*}$ & 0 & $16^{*}$ & 14 & 0 \\
\hline Students taste vegetables from the garden & 8 & $10^{*}$ & 2 & 3 & $6^{*}$ & 1 & 1 & 1 & 1 & 12 & $17^{*}$ & 4 \\
\hline Students learn how to cook & $10^{*}$ & 7 & 1 & $4^{*}$ & $4^{*}$ & 2 & 0 & 1 & $2^{*}$ & $14^{*}$ & 12 & 5 \\
\hline Teachers link fruit \& vegetable intake and health & 6 & $14^{*}$ & 0 & $5^{*}$ & $5^{*}$ & 0 & 1 & $2^{*}$ & 0 & 12 & $21^{*}$ & 0 \\
\hline Students learn about nutrition & 8 & 11 & 1 & 3 & $7^{*}$ & 0 & 1 & $2^{*}$ & 0 & 12 & $20^{*}$ & 1 \\
\hline Students learn about plant growth & 5 & $14^{*}$ & 1 & 3 & $7^{*}$ & 0 & 1 & $2^{*}$ & 0 & 9 & $23^{*}$ & 1 \\
\hline Students learn about vegetable composition & $11^{*}$ & 3 & 5 & $6 *$ & 1 & 1 & 1 & $2^{*}$ & 0 & $18^{*}$ & 6 & 6 \\
\hline Students learn about healthy eating & 8 & $12^{*}$ & 0 & 3 & $7^{*}$ & 0 & 1 & $2^{*}$ & 0 & 12 & $21^{*}$ & 0 \\
\hline Teachers talk about obesity & $8^{*}$ & 3 & $8^{*}$ & $6^{*}$ & 0 & 2 & 1 & $2^{*}$ & 0 & $15^{*}$ & 5 & 10 \\
\hline
\end{tabular}

$\mathrm{SA}=$ strongly agree; $\mathrm{A}=$ agree; $\mathrm{D}=$ disagree.

${ }^{*}$ Mode response. 
and spend more time in the garden. The biggest barrier to this expansion was financial (29\% of responses) and also the involvement of people to be in charge of the garden (16\%). Many respondents (24\%) indicated time as a major issue. However, many failed to nominate any specific negative aspect of having a food garden (particularly in the subtropical metropolitan area, where $33 \%$ offered no negative aspects). Otherwise, a common negative aspect of the garden was vandalism. For positive aspects, 'growing vegetables', 'learning about vegetables' and 'eating fresh' were the most common responses.

\section{Schools witbout a food garden}

For this questionnaire, $80 \%$ of schools had no garden, of which $22 \%$ opted not to participate in the interview. Of schools that participated, $12 \%$ were very interested in establishing a food garden and many schools (64\%) wanted more information about how to establish such gardens. About $20 \%$ of interviewees indicated their school was not interested in this kind of project. The most common needs identified by respondents to establish a garden were soil, space, a fence and funds. Indeed, the lack of space was the biggest issue for schools in the subtropical metropolitan region, followed by a fence against vandalism (also indicated by some tropical schools). In the tropical continental region, water was one of the most common needs reported.

Some respondents (17\%) nominated the time required for garden maintenance as being the major negative aspect after vandalism (28\%). However, 19\% of respondents nominated no specific barrier to garden establishment. Climate was a major concern for respondents from the tropical humid (21\%) and tropical continental regions (18\%), as were the lack of water during the dry season and the heat during summer months. This was not seen as an issue for the subtropical metropolitan schools.

Almost all schools (84\%) thought that a garden could help students to eat healthier and many schools said they would use a vegetable garden for class activities if they had one (88\%). One of the main issues in the subtropical metropolitan (Brisbane) region was space, particularly in the inner city. Some schools addressed this barrier by growing plants in container gardens (i.e. wooden boxes). Schools in regional areas were not constrained by space, but were often confronted with security issues such as vandalism and wildlife.

\section{Discussion}

A major observation from the present study was the variation in prevalence of functioning food gardens associated with differences in climate between the three sampling regions. Of particular note was the absence of functioning gardens in the tropical continental region, in conjunction with a history of gardening initiation and abandonment (see Table 1). There are inherent weaknesses in classifying communities on geographical location alone ${ }^{(17)}$, where oversimplification such as rural-urban dichotomy can mask the effects of associated issues such as employment, access to services, size of communities, education and family affluence levels. Notwithstanding this, respondents confirmed climate as a major garden sustainability issue.

One conclusion to be drawn from this is that while school gardens are one potential pathway for the development of nutrition education tools, the establishment of a permanent garden is not suited to all environments. In regions with a short growing season, it may be more appropriate to consider school gardens as a cyclical process, with initiation occurring every year and the site left fallow during the dry times, thus working with, rather than against, environmental factors. The pedagogic association of season and food has some currency. There is clear evidence that price and access are key determinants of vegetable and fruit intake ${ }^{(18)}$. Produce in season is markedly cheaper, an important consideration for those on marginal incomes and often at higher risk of chronic disease in general ${ }^{(19)}$. In addition, proximity to production (inherent in the 'food miles' concept) is an emerging consideration linking food choice to environmental issues $^{(20)}$, which equates to choosing foods in season.

Although not specifically used as the ground theory for the questionnaires in the present study, Self Determination Theory (SDT) provides one potential interpretation of the study findings. It assumes two separate phases for school food gardens: initiation and continuation. In the context of SDT, dietary and physical activity behaviours of individuals are influenced by both intrinsic and extrinsic motivational forces. Health-related interventions most commonly focus on extrinsic motivation, governed by factors such as the physical environment (availability of foods in school canteens, access to sports facilities) and curriculum (passing exams). Extrinsic motivational forces are useful in the initial engagement of behavioural change $^{(21)}$, but intrinsic motivation associates more strongly with sustained long-term behavioural change as noted in smoking cessation programmes ${ }^{(22)}$. Intrinsic motivation is associated with high levels of enjoyment and (an implied) long-lasting interest in an activity. A separate survey tool grounded in SDT would be required to confirm the suitability of this interpretation.

Diet interventions, especially those related to overweight and obesity in children, are notoriously unable to sustain long-term adherence ${ }^{(23)}$. The initial aims for garden establishment summarized in Table 2 comprise mainly factors more likely to align with intrinsic motivation, especially since gardens emerged in the absence of specific policy direction. The added observation that many gardens had been in operation for a number of years strengthens the argument that a high level of intrinsic motivation has driven this activity. The challenge for nutrition intervention design is to develop ways to 
harness the intrinsic motivation behind grass-roots-driven initiatives such as school gardens. Identification of key motivational processes would require investigative tools (i.e. questionnaires) grounded in SDT and are beyond the scope of the methodology in the present study.

The school gardens reported in the present study were established predominantly as teaching resources. It is not surprising then that integration into the formal curriculum was a major consideration for teachers. This is an important process in terms of nutrition education, since the combination of gardening and classroom instruction has been shown more efficient to increase knowledge of students than classroom nutrition education alone ${ }^{(24)}$.

There was a range of pedagogic activities reported by respondents. The most notable were classroom activities where students tasted, prepared, cooked and otherwise learned about the foods they had produced. Of particular note were the opportunities to present new vegetables to students. Indeed, past positive experiences with vegetables and fruit can influence students' preferences and increase their consumption ${ }^{(25)}$. There is also an opportunity to translate recommendations of quantity into a practical reality, an important personal determinant of fruit and vegetable intake ${ }^{(26)}$.

There was a bimodal response for teachers using the garden as an opportunity to discuss the issue of overweight and obesity with their students (see Table 4). Interestingly, some teachers reported avoiding this topic because some of their students were overweight, indicating a potential need for guidelines on how to address this important health issue in an objective and non-personal way. Class discussions about overweight and obesity can easily become personalized since overweight individuals are easy to identify. This could lead to negative outcomes, since the association between overweight and depression in children is mediated in part by shame $^{(27)}$. Non-diet wellness interventions with dietary behaviour outcomes have been acknowledged as one solution to general feelings of failure and frustration associated with contemporary dieting practices ${ }^{(28)}$. The school food garden concept extends this notion further, in the form of an 'environmental wellness' intervention.

Golan and Crow ${ }^{(29)}$ have observed that parental involvement enhances the success of weight-related prevention and treatment interventions in children. In some schools, parents led lunch clubs and were heavily involved in extracurricular activities. However, this was not the case for most schools. Although its population is sparse at $2 \cdot 1$ persons per square kilometre, the state of Queensland is highly centralized, with a large proportion (65\%) of its approximately 3.6 million inhabitants ${ }^{(30)}$ residing in the metropolitan centres located in the south-east of the state. Consequently, the tropical continental region is relatively sparsely populated, with accessibility to schools limited. This region was also characterized by having relatively little parental involvement in the gardens. Since the avail- ability of parents is likely to vary substantially between communities, an expanded range of options for parental participation is useful. One potential pathway observed in some schools was the use of the school gardens as a hub for establishment of household food gardens.

While the use of gardening in schools seems to be relatively widespread ${ }^{(8,9)}$, the reporting of the impact of this activity in terms of health, education or other outcomes seems comparatively scant. The demands of randomized controlled trial design and well-defined interventions ${ }^{(31)}$ present difficulties in reporting the impact of gardens other than through short-term programmes with precise associated curricula ${ }^{(13,15,32)}$. Community gardens are often established with primary objectives other than diet and nutrition outcomes ${ }^{(9)}$ and an organic process of intervention development ${ }^{(12)}$, rather than a single, specific intervention. Hence it is likely that these rich, communitybased, community-driven interventions are under-reported. Even studies on gardens with well-defined intervention protocols ${ }^{(13)}$ have difficulties in including any formal experimental control.

The present study indicates that school food gardens are not a defined, single intervention, but a diverse range of garden profiles determined by factors such as initial aims for garden initiation (environment, health, finance, behaviour management), school size (class-based activity $v$. a whole-of-school resource) and community involvement (community-based gardens visited by schools; gardens established in schools related specifically to an education programme; school-based community gardens which are established with long-term intentions, not necessarily linked to defined curriculum and often established in conjunction with the broader non-school community). Each profile has unique potential impacts on students, schools and the broader community. A classification framework incorporating the above attributes would facilitate a stronger evidence base for school food gardens as a health promotion initiative.

These findings extend the feasibility profile for school gardens reported by Graham et al. ${ }^{(8)}$ in terms of providing tangible examples of how gardens are used in practice. Although the present study represented a smaller sample size, the response rate of our telephone survey was two-fold that of the mail-out survey conducted by Graham et al. ${ }^{(8)}$. It is acknowledged that these data provide a cross-section of activity in tropical and subtropical climates. However, many of the general issues are likely to be the same in temperate climates, notwithstanding certain specific issues such as length of growing season, types of plants, local agricultural habits and social issues, which may vary.

The findings reported in the present study are of a cross-sectional and retrospective nature. Therefore, a certain degree of caution is required in applying these findings in a prospective context. Prospective trials are required to determine if the factors associated with success in the present study actually work. 
The present study focused on actual practice in relation to school-based food gardens, and the questionnaires used were based on previous findings in similar samples of school gardens ${ }^{(9,11)}$. The absence of a formal grounded theory underpinning these questionnaires could be interpreted as a potential weakness of the study. The development of a deeper understanding of the underlying motivations for initiation and continuation of school-based food gardens would be best served through the use of survey instruments grounded in established theories such as $\operatorname{SDT}^{(21,22)}$.

\section{Conclusion}

The present study shows that school gardens in these diverse tropical and subtropical regions of Australia are a prevalent education resource. The absence of a centralized curriculum support for school gardens confirms these initiatives as largely teacher-dependent, grass-roots initiatives. Indeed, teacher involvement emerged as an essential component in garden establishment and sustainability. Of particular interest is the intrinsic motivation associated with grass-roots involvement, often difficult to generate or harness in health promotion interventions.

Food gardens are used in a diverse range of curriculum areas and as an addition to extracurriucular school life. Previous studies on school gardens have applied an assumption that such gardens are a health promotion intervention. However, results from the present study indicate that health was not the most prominent/common reason for garden establishment. Indeed, it may be more constructive to view school gardens as an educational initiative (driven by factors other than health) with collateral health-promoting outcomes.

A clear pathway to better understanding of the health effects of school food gardens is the development of protocols to better define the nature of such gardens.

\section{Acknowledgements}

There are no conflicts of interest, the present work was not funded by any agency, and there are no acknowledgements. S.S. designed and implemented the study, analysed the data and wrote the paper. A.B. developed the questionnaire, conducted the interviews and completed preliminary data analysis. Both authors read and approved the final manuscript.

\section{References}

1. Saland JM (2007) Update on the metabolic syndrome in children. Curr Opin Pediatr 19, 183-191.

2. World Cancer Research Fund/American Institute for Cancer Research (1997) Food, Nutrition, Physical Activity and the Prevention of Cancer: A Global Perspective. Washington, DC: AICR.
3. Caballero B (2001) Early nutrition and risk of disease in the adult. Public Health Nutr 4, 1335-1336.

4. Anderson AS, Porteous LEG, Foster E, Higgins C, Stead M, Hetherington M, Ha MA \& Adamson AJ (2005) The impact of a school-based nutrition education intervention on dietary intake and cognitive and attitudinal variables relating to fruits and vegetables. Public Health Nutr 8, 650-656.

5. Bere E \& Klepp K-I (2005) Changes in accessibility and preferences predict children's future fruit and vegetable intake. Int J Behav Nutr Phys Act 2, 15-23.

6. Cockroft JE, Durkin M, Masding C \& Cade JE (2005) Fruit and vegetable intakes in a sample of pre-school children participating in the 'Five for All' project in Bradford. Public Health Nutr 8, 861-869.

7. Kristjansdottir AG, Thorsdottir I, De Bourdeaudhuij I, Due P, Wind M \& Klepp KI (2006) Determinants of fruit and vegetable intake among 11-year-old schoolchildren in a country of traditionally low fruit and vegetable consumption. Int J Behav Nutr Phys Act 3, 41.

8. Graham H, Beall D, Lussier M, McLaughlin P \& ZidenbergCherr S (2005) Use of school gardens in academic instruction. J Nutr Educ Behav 37, 147-151.

9. Somerset S, Ball R, Flett M \& Geissman R (2005) Schoolbased community gardens: re-establishing healthy relationships with food. J Home Econ Inst Aust 12, 25-33.

10. Phelan S, Wyatt HR, Hill JO \& Wing RR (2006) Are the eating and exercise habits of successful weight losers changing? Obesity (Silver Spring) 14, 710-716.

11. Somerset S \& Markwell K (2008) Impact of a school-based food garden on attitudes and identification skills regarding vegetables and fruit: a 12-month intervention trial. Public Health Nutr (Epublication ahead of print version).

12. Armstrong D (2000) A survey of community gardens in upstate New York: implications for health promotion and community development. Health Place 6, 319-327.

13. Lautenschlager L \& Smith C (2007) Understanding gardening and dietary habits among youth garden program participants using the Theory of Planned Behavior. Appetite 49, 122-130.

14. Wakefield S, Yeudall F, Taron C, Reynolds J \& Skinner A (2007) Growing urban health: community gardening in South-East Toronto. Health Promot Int 22, 92-101.

15. McAleese JD \& Rankin LL (2007) Garden-based nutrition education affects fruit and vegetable consumption in sixthgrade adolescents. J Am Diet Assoc 107, 662-665.

16. Australian Bureau of Meteorology (2004) Climate Data Online. http://www.bom.gov.au/climate/averages/ (accessed November 2008)

17. Wang Y \& Beydoun MA (2007) The obesity epidemic in the United States - gender, age, socioeconomic, racial/ethnic, and geographic characteristics: a systematic review and meta-regression analysis. Epidemiol Rev 29, 6-28.

18. Glanz K, Basil M, Malback E, Goldberg J \& Snyder D (1998) Why Americans eat what they do: taste, nutrition, cost, convenience and weight control concerns as influences on food consumption. J Am Diet Assoc 98, 1118-1126.

19. Everson SA, Maty SC, Lynch JW \& Kaplan GA (2002) Epidemiological evidence for the relation between socioeconomic status and depression, obesity and diabetes. J Psychosom Res 53, 891-895.

20. Lang T \& Heasman M (2004) Food Wars. London: Earthscan.

21. Dishman RK \& Sallis JF (1994) Determinants and interventions for physical activity and exercise. In Physical Activity, Fitness, and Health: International Proceedings and Consensus Statement, pp. 214-238 [C Bouchard, RJ Shephard and T Stephens, editors]. Champaign, IL: Human Kinetics Publishers.

22. Curry SJ, Wagner EH \& Grothaus LC (1991) Evaluation of intrinsic and extrinsic motivation interventions with a selfhelp smoking cessation program. J Consult Clin Psychol 59, 318-324. 
23. Gibson LJ, Peto J, Warren JM \& dos Santos Silva I (2006) Lack of evidence on diets for obesity for children: a systematic review. Int J Epidemiol 35, 1544-1552.

24. Morris JL \& Zidenberg-Cherr S (2002) Garden-enhanced nutrition curriculum improves fourth-grade school children's knowledge of nutrition and preferences for some vegetables. $J$ Am Diet Assoc 102, 91-93.

25. Devine CM, Wolfe WS, Frongillo EA Jr \& Bisogni CA (1999) Life-course events and experiences: association with fruit and vegetable consumption in 3 ethnic groups. J Am Diet Assoc 99, 309-314.

26. Perez-Rodrigo $C$, Wind $M$, Hildonen $C$, Bjelland $M$, Aranceta J, Klepp K-I \& Brug J (2005) The Pro Children intervention: applying the intervention mapping protocol to develop a school-based fruit and vegetable promotion programme. Ann Nutr Metab 49, 267-277.

27. Sjoberg RL, Nilsson KW \& Leppert J (2005) Obesity, shame, and depression in school-aged children: a populationbased study. Pediatrics 116, e389-e392.
28. Bacon L, Keim NL, Van Loan MD, Derricote M, Gale B, Kazaks A \& Stern JS (2002) Evaluating a 'nondiet' wellness intervention for improvement of metabolic fitness, psychological well-being and eating and activity behaviors. Int J Obes Relat Metab Disord 26, 854-865.

29. Golan M \& Crow S (2004) Parents are key players in the prevention and treatment of weight-related problems. Nutr Rev 62, 39-50.

30. Australian Bureau of Statistics (2004) Queensland in Review, 2003. Canberra: Australian Bureau of Statistics.

31. Atienza AA \& King AC (2002) Community-based health intervention trials: an overview of methodological issues. Epidemiol Rev 24, 72-79.

32. Nanney MS, Johnson S, Elliott M \& Haire-Joshu D (2007) Frequency of eating homegrown produce is associated with higher intake among parents and their preschoolaged children in rural Missouri. J Am Diet Assoc 107, 577-584 